\title{
Improvement Properties of Cohesion-Less Soil Using Recycled Bassanite
}

\author{
Masaki Kobayashi ${ }^{1}$, Aly Ahmed ${ }^{2}$ and Keizo Ugai $^{3}$ \\ 1. Environmental Business Department, DC Co., Ltd., Tokyo 210-005, Japan \\ 2. Civil Engineering Department, Beni-Suef University, Beni-Suef 62512, Egypt \\ 3. Civil and Environmental Engineering Department, Gunma University, Gunma 376-8515, Japan
}

\begin{abstract}
Solid waste management is a serious problem over the world. Therefore, reduction, re-use and recycling of waste have become major issues in recent days. Gypsum waste plasterboard is considered one example of these waste materials. This study evaluates the use of recycled bassanite, which is derived from gypsum waste plasterboard, to enhance the performance of two types of cohesion-less soil. Recycled bassanite was utilized as a stabilizing agent to improve both compressive and splitting strengths of the tested soil. The effect of bassanite content, soil type, water content and curing time were investigated to explore the behavior of treated soil with recycled bassanite. Test results showed that increase of bassanite content is associated with increase in optimal moisture content, while no significant increase in the dry unit weight was observed. Both compressive and splitting tensile strengths enhanced with the additives of recycled bassanite. The increase of bassanite content had a more significant effect on the compressive strength compared with the effect on tensile strength. The use of recycled bassanite to enhance the strength of sandy soil had a more significant effect compared with silty soil. The effect of curing time on the strength of treated samples was more significant in early curing ages compared with late curing ages. The strength decreased significantly in case of stabilized samples prepared with water content at the wet-side of the compaction curve. However, insignificant decrease in the strength of the stabilized sample was detected with moisture content at the dry-side of compaction curve. This research meets the challenges of our society to reduce the quantities of gypsum wastes, producing useful material from waste materials that will help to a sustainable society.
\end{abstract}

Key words: Soil stabilization, compressive strength, recycled bassanite, cohesion-less soil, splitting strength.

\section{Introduction}

Recently, researchers are focused on obtaining a desirable way to eliminate waste materials by using them as alternatives in the applications of civil and industrial engineering. Gypsum waste plasterboard is considered one example of these waste materials. Large quantities of gypsum plasterboard, approximately 80 million tons in the world, are produced annually. Around $85 \%$ of this production accounts for Europe, USA and Japan. Out of the latter figure, about 15 million tons is sent to landfill sites [1]. Plasterboard is made from gypsum sheets covered on both sides with paper sheets. Consequently, increasing the amount of gypsum waste plasterboard results in

Corresponding author: Masaki Kobayashi, manager, research fields: geotechnical and environmental engineering. E-mail: kobayashi_masaki@dccorp.jp. more quantities, which are disposed in landfills. Hence, it is deemed necessary to find alternative solutions to such problems due to the following reasons: First, gypsum waste plasterboard in landfills is known under certain circumstances to cause hydrogen sulfide gasses, which are potentially harmful for human and animals; Second, there is currently an increase in the cost of disposal in landfill and decrease in available ground spaces specified for landfills sites; Third, landfill regulations and environmental laws in Japan require that quantities based on gypsum materials are disposed to landfills, and that the waste must be sent to the controlled landfill site, which in turn leads to increase in disposal cost.

Several researchers have conducted investigations to improve the physical and mechanical properties of 
soil by using different types of waste materials, such as cement kiln dust, fly ash, bottom ash, blast furnace slag, stone dust and factory-waste roof shingles [2-6]. Most of the previous studies investigated the use of recycled gypsum waste plasterboard in agriculture applications, while a few studies focused on the use of gypsum wastes in civil and construction engineering applications. The new unfired gypsum-clay blocks were manufactured by using processed plasterboard from recycled sources. The blend of production blocks comprises $50 \%$ of recycled plasterboard. Results indicated that the product has a good physical properties compared with natural clay [7]. Laboratory and field investigations were conducted to develop effective novel cementation mixes using recycled gypsum and a range of mineral wastes for road foundation construction. For this purpose, a series of laboratory trials were carried out to determine the optimum proportions of recycled gypsum and mineral wastes of a binder paste to achieve the highest compressive strength. The optimum combination for the novel binder was a mix of $15 \%$ recycled gypsum from waste plasterboard, 5\% bypass dust and $80 \%$ basic oxygen slag, which gave a high compressive strength. Results indicated that plasterboard waste can be used in low-strength concrete mixes for the foundations of minor roads and car parks [8].

Generally, recycled bassanite derived from gypsum waste plasterboard has a potential to be used as a cementation material because gypsum is the main key of cementation products. Therefore, the main objective of this research is to investigate the use of recycled bassanite derived from gypsum waste plasterboard as a stabilized agent to improve both mechanical properties and strength of cohesion-less soil.

\section{Materials and Methods}

Three types of materials, which include two different types of soil, recycled bassanite and portland cement, were used. The two used soil types were brought from Gunma prefecture, Japan. The two types of soil were named as soil-A and soil-B. All physical and mechanical properties of tested soils are shown in Table 1 . The grain size distribution curves for all the tested soils are shown in Fig. 1.

Recycled bassanite used herein was derived from gypsum waste plasterboard. The crushed plaster gypsum waste $\left(\mathrm{CaSO}_{4} \cdot 2 \mathrm{H}_{2} \mathrm{O}\right)$ was heated at a temperature ranging from $130{ }^{\circ} \mathrm{C}$ to $160{ }^{\circ} \mathrm{C}$ for a certain time results in a hemi-hydrate calcium sulphate $\left(\mathrm{CaSO}_{4} \cdot 0.5 \mathrm{H}_{2} \mathrm{O}\right)$ with three quarters of the water molecules removed. Firstly, gypsum waste plasterboard was pulverized and then screened to remove any impurities such as papers, paints and any solid material. Afterward, the powder of gypsum waste was placed on a specified plate and then the process of heating was started. The preparation of

Table 1 Physical and mechanical properties of tested soils.

\begin{tabular}{lll}
\hline Property & Soil A & Soil B \\
\hline Effective diameter, (D10), (mm) & 0.15 & 0.06 \\
Nominal mean size, (D50), (mm) & 0.21 & 0.15 \\
Uniformity coefficient, (Cu) & 1.53 & 2.72 \\
Curvature coefficient, (Cc) & 0.94 & 1.02 \\
Passing from sieve No. 200 & 0.40 & 11.30 \\
Max. dry unit weight, (kN/m ${ }^{3}$ ) & 15.7 & 14.28 \\
Optimum moisture content, (\%) & 13.20 & 20.40 \\
Specific gravity, Gs & 2.60 & 2.67 \\
Max. void ratio & 0.85 & 1.28 \\
Min. void ratio & 0.60 & 0.79 \\
Soil classification (USCS) & SP & SP \\
Soil classification (AASHTO) & A-3 & A-2-4 \\
& Fine sand & Silty sand \\
\hline
\end{tabular}

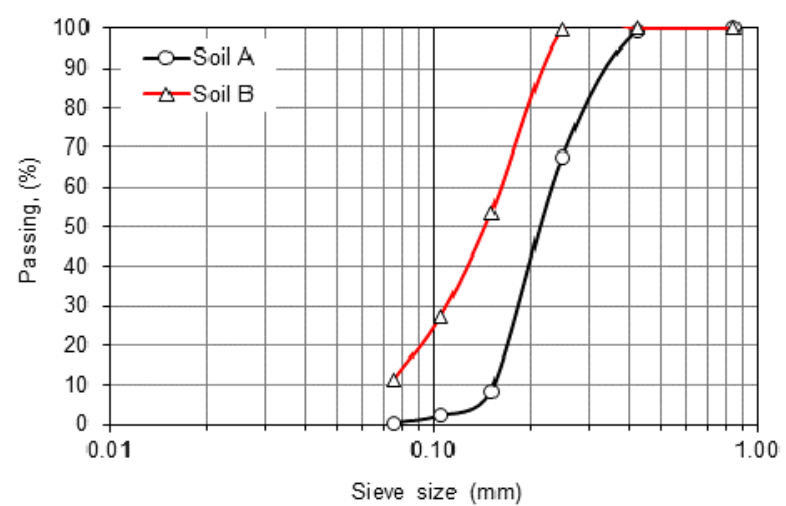

Fig. 1 Grain size distribution curve for different soil types used. 
recycled bassanite was done in some construction companies in Gunma prefecture, Japan and Fig. 2 is a schematic diagram for preparing the recycled bassanite. Four different contents of recycled bassanite $0,5 \%, 10 \%$ and $15 \%$ based on dry soil weight were investigated.

Portland cement was used with a content of $3 \%$ by dry soil mass, which was added to test soil sample. The main reason for the addition of cement is to prevent the solubility of gypsum when water was introduced since hydrate calcium sulphate $\left(\mathrm{CaSO}_{4} \cdot 2 \mathrm{H}_{2} \mathrm{O}\right)$ is a known water-soluble material.

\section{Sample Preparation}

The effect of using recycled bassanite on the strength of tested soil was evaluated by conducting a series of unconfined compression and splitting tensile strength tests. Cylindrical samples having a $50 \mathrm{~mm}$ diameter and $100 \mathrm{~mm}$ height were used. The cylindrical mold, which was used to form the soil samples, was made from high grade plastic with $5 \mathrm{~mm}$ thickness to resist any external pressure during the process of compaction. The reason of using plastic molds was to prevent the friction between soil samples and the inner sides of the mold during sample extraction. In addition, the use of oil to lubricate the inner sides of the mold was to make sure that no friction will be occurred during sample extraction. The samples were placed into the molds and compacted statically using a static method by hydraulic Jack to reach the required density. By knowing mold volume, which is constant for all tests

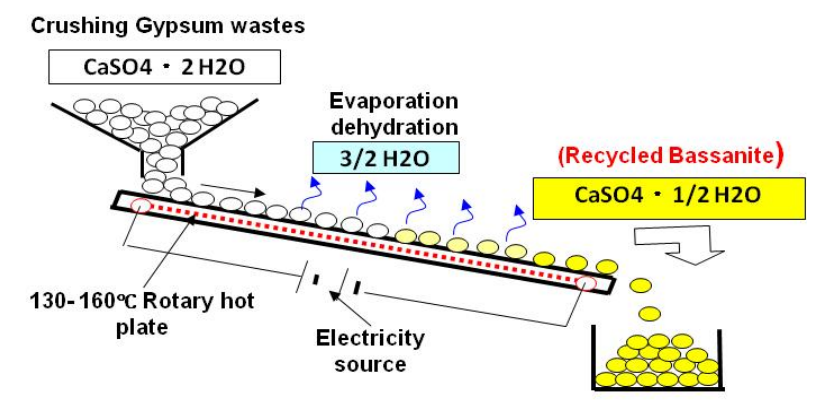

Fig. 2 Schematic diagram for producing recycled bassanite from gypsum waste plasterboard [9]. and the desired density, the weight of soil was determined to validate the required density. Homogeneity of the samples was of main concern during preparation and extraction. The soil samples were extracted from the molds after $24 \mathrm{~h}$. More details for preparing stabilized soil samples were described previously [5, 6]. All samples tests were conducted after seven days of curing at temperature $\left(21 \pm 1{ }^{\circ} \mathrm{C}\right)$ and relative humidity more than $90 \%$. Some samples were tested after 3, 14, 28 and 56 days of curing under the same conditions to investigate the effect of curing time on the strength of samples treated with recycled bassanite.

All tests were conducted at the optimal moisture content and maximum dry unit weight to simulate field conditions. A standard compaction test was carried out to determine the dry density/moisture-content relationships of untreated and treated soil with different contents of recycled bassanite, according to ASTM D698-70 specifications. The oven-dried soil and recycled bassanite mixtures was firstly dry mixed then the amount of water tap was added to obtain the moisture content for all tested soils.

\section{Results and Discussion}

The dry density/moisture-content relations for soils A and B treated with different contents of recycled bassanite are shown in Figs. 3 and 4, respectively.

It is clear that the increase of recycled bassanite content is associated with a significant increase in optimum moisture content in both the soil types used. It is attributed to two reasons: Firstly, due to the tendency of hemi-hydrate calcium sulphate $\left(\mathrm{CaSO}_{4} \cdot 0.5 \mathrm{H}_{2} \mathrm{O}\right)$ to obtain the three quarters of the water that was missed before during heating process, in order to change to hydrate calcium sulphate $\left(\mathrm{CaSO}_{4} \cdot 2 \mathrm{H}_{2} \mathrm{O}\right)$; The second reason is related to when fine content such as recycled bassanite was mixed with soil, more water was required in compaction in order to achieve the maximum dry unit weight [10]. In 


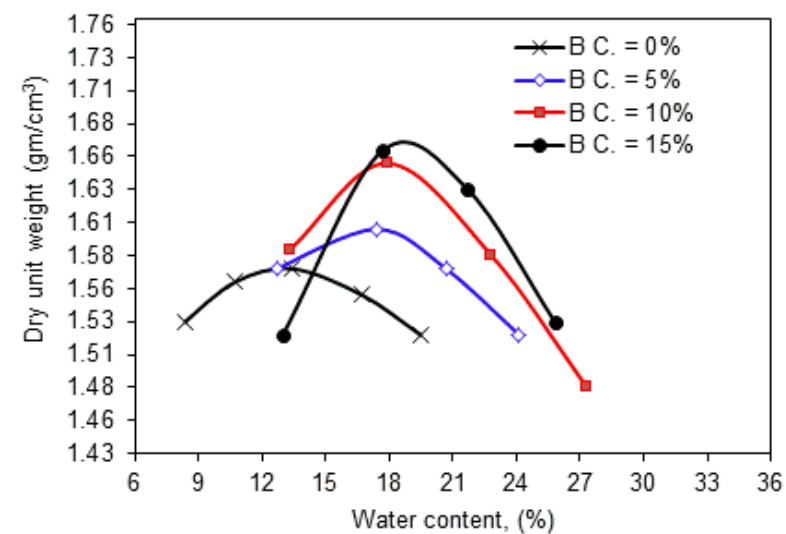

Fig. 3 Dry density/moisture-content curves for tested soil-A at different contents of recycled bassanite used.

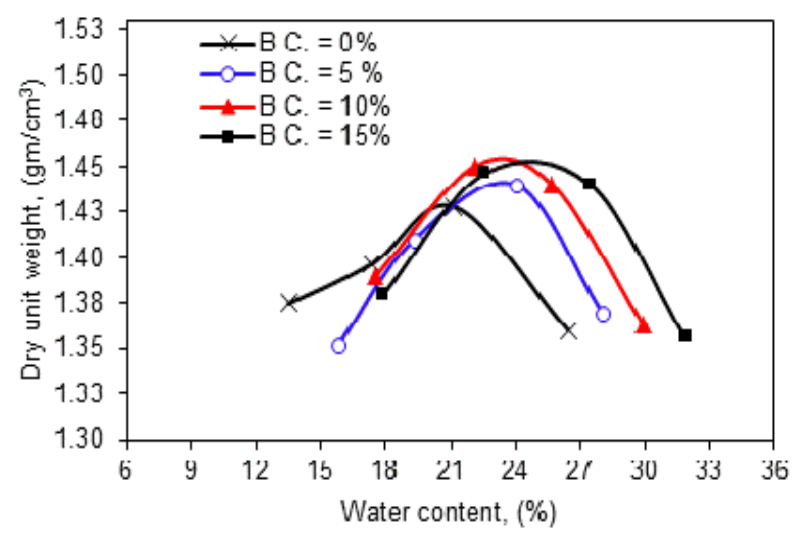

Fig. 4 Dry density/moisture-content curves for tested soil-B at different contents of recycled bassanite used.

the case of soil type B (silty soil), the increase of bassanite content up to $15 \%$ was associated with a slightly increase in dry unit weight. This was attributed to the calcium component in bassanite, which promotes soil particles to flocculate. Thus, attraction between soil particles was developed due to this property of flocculation. It may be assumed that the flocculation occurred due to the fine components of the soil which normally carry negative charges and attract calcium, which carries two positive charges. This behavior could be related to the tested soil-B comprising more than $10 \%$ content of silty clay, which can subsequently behave as fine minerals. The reason of the slightly increase of dry unit weight is probably related to the increase of optimal moisture content in the soil-bassanite mixture as compared to pure soil. Consequently, the maximum dry unit weight increased slightly. While in the case of soil type A (fine sand), slight increase in dry unit weight was related to the particles of bassanite which are very fine compared to soil particles. That makes it easy for some bassanite particles to fill the small pores within the particles of sandy soil. It is difficult from a practical view to completely fill the pores during compaction process in the case of pure sand. For the same volume of compacted sample, the weight of the bassanite-sand mixture was slightly higher than the weight of pure sand that was associated with the slight increase in dry unit weight. On the contrary, if the difference between soil particles was high such as in coarse sand, the dry unit weight would be decreased.

The results presented herein are only for soil-B because the same results were obtained with the other type of soil-A. The results of unconfined compression tests, stress-strain relationship, for soil-B type treated with different contents of recycled bassanite are shown in Fig. 5. Obviously, the compressive strength increased with the increase of bassanite content. These results suggested that recycled bassanite can be used as a stabilizing material in ground improvement projects. These results are in agreement with the previous results [9, 11]. Improvement indexes for both compressive and splitting tensile strengths against the content of bassanite are shown in Fig. 5. Improvement stress index was obtained by dividing the ultimate

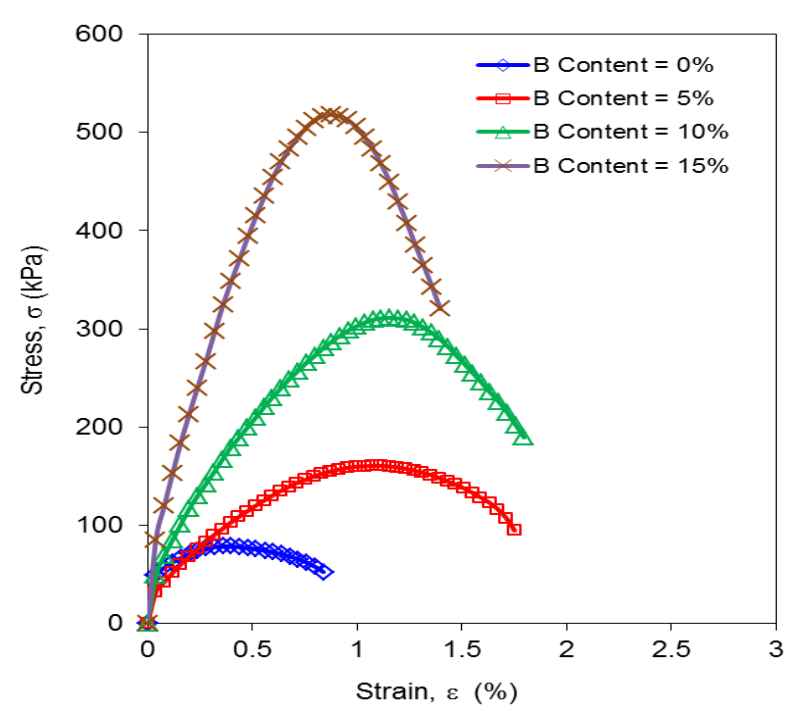

Fig. 5 Stress-strain relationships for soil-B with different bassanite contents. 
stress for the treated sample to the ultimate stress of identical un-treated sample. Fig. 6 indicates that both compressive and splitting strengths were enhanced with the increase of recycled bassanite content. The improvement in compressive strength was more significant than that in tensile strength. This is attributed to the fact that stabilized soil cement, which is weak in tension compared with compression state. An increase of bassanite content up to 15\% enhanced the improvement of splitting strength compared to other lower contents used, as shown in Fig. 5. To sum up, the use of recycled bassanite as a stabilizing agent to improve the strength of cohesion-less soil can be acceptable in both compressive and splitting strengths.

Fig. 7 shows the stress-strain relationship for different two soil types treated with $10 \%$ content of recycled bassanite. It can be observed that the higher performance was obtained in the case of soil-A compared with the case of soil-B. The use of bassanite had a significant effect on the strength enhancement of sandy soil compared to silty soil. This effect could be due to the friction between soil particles of sandy soil was higher than that in silty soil. Besides, the developed cohesion between particles of sandy soil was greater than that in silty soil due to the contact surface area between sand soil particles and bassanite is strong. Thus, the effect of using bassanite to enhance the strength of sandy soil was much pronounced compared to silty sand soil. The same behavior was obtained in the case of splitting tensile strength.

To investigate the effect of water content state on the strength of soil treated with recycled bassanite, three different moisture contents including OMC (optimal moisture content) and moisture contents in dry and wet sides that corresponding to $95 \%$ of maximum dry unit weight, were used, respectively. The main reason for the use of $95 \%$ maximum dry unit weight was to simulate filed conditions. Unconfined compression test was conducted on treated samples of soil-B with recycled bassanite contents of $5 \%$ and $15 \%$, respectively for different investigated cases of water contents. The suggested contents of $5 \%$ and $15 \%$ of recycled bassanite were representing the smallest and highest content. The tests were conducted after 7 and 14 days of curing ages to investigate the effect of water content on the age of treated samples. The effects of water content on the strength of treated samples are shown in Figs. 8 and 9. It is clear that for both age of samples, the high strength was obtained with samples prepared at optimal moisture content compared to other two used

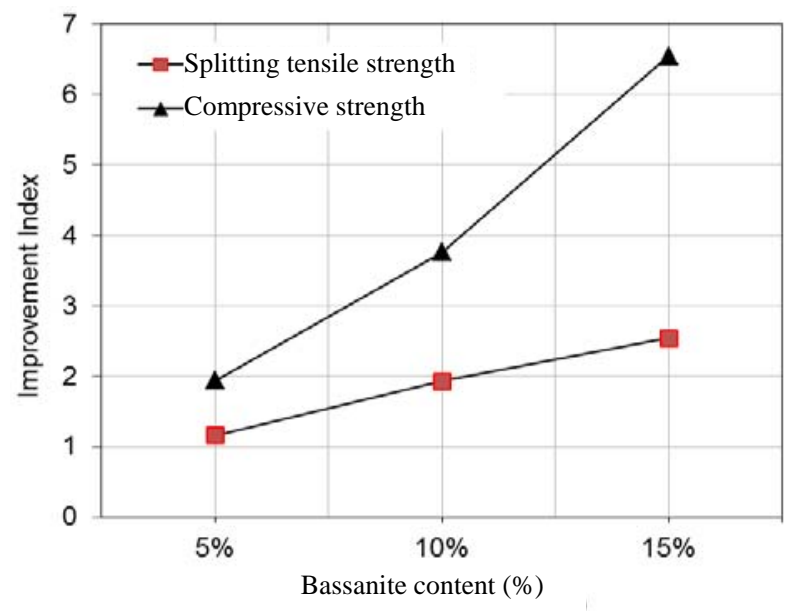

Fig. 6 Improvement index for both compressive and splitting tensile strengths in case of soil-B treated with different bassanite contents.

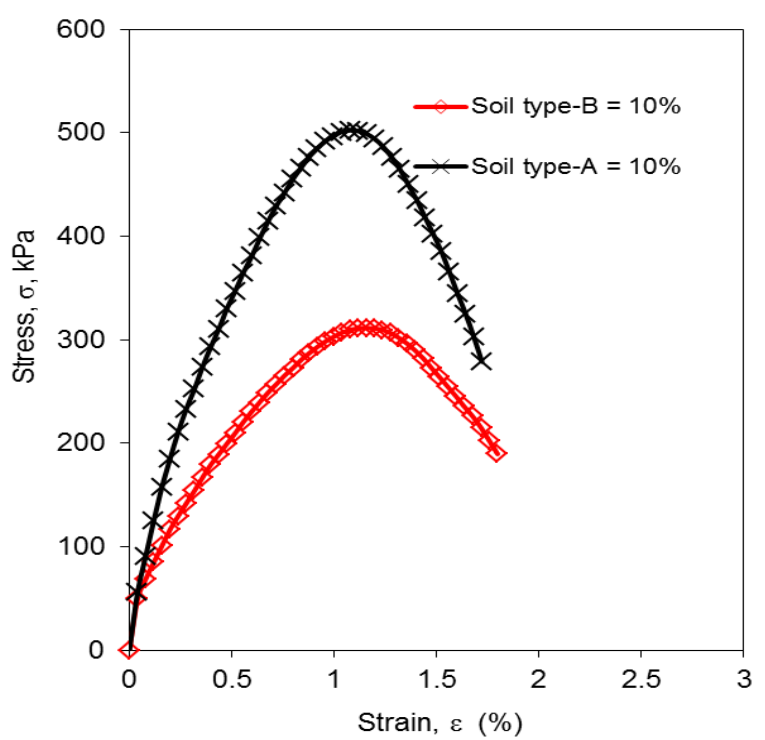

Fig. 7 Stress-strain relationships for different soil types used treated with $10 \%$ content of recycled bassanite. 
water contents. These results are consistent with the expected routine results of compaction test. The effect of water content on the strength of 7-day cured samples was much pronounced than the 14-day cured samples. The latter difference may be due to the increase of curing age of the samples. This was associated with the increase of strength and consuming most of the excess water as a result of the reaction between soil particles and bassanite.

Also, it can be noted that the effect of water content on the samples having highest bassanite content was more prominent than the samples having smallest bassanite content. This behavior could be related to both increase in bassanite content and water content, as illustrated before. Subsequently, the effect of water

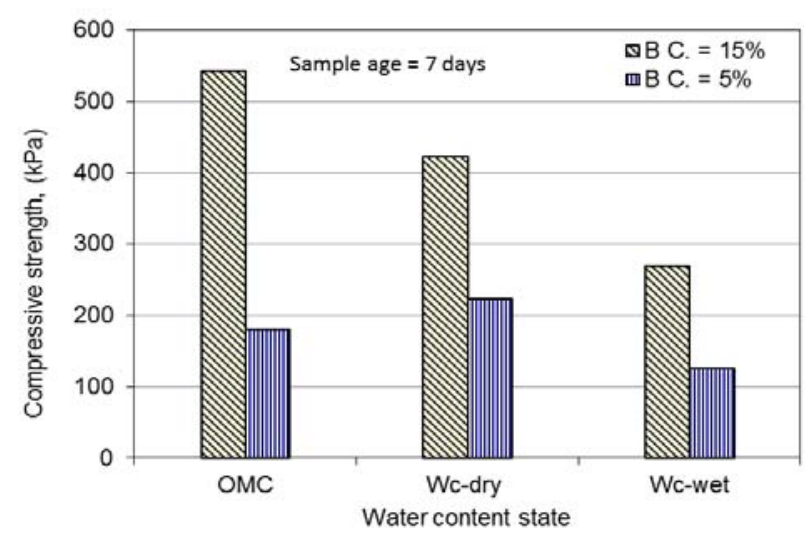

Fig. 8 Ultimate compressive strength against water content for soil type-B treated with recycled bassanite and tested after seven days curing age.

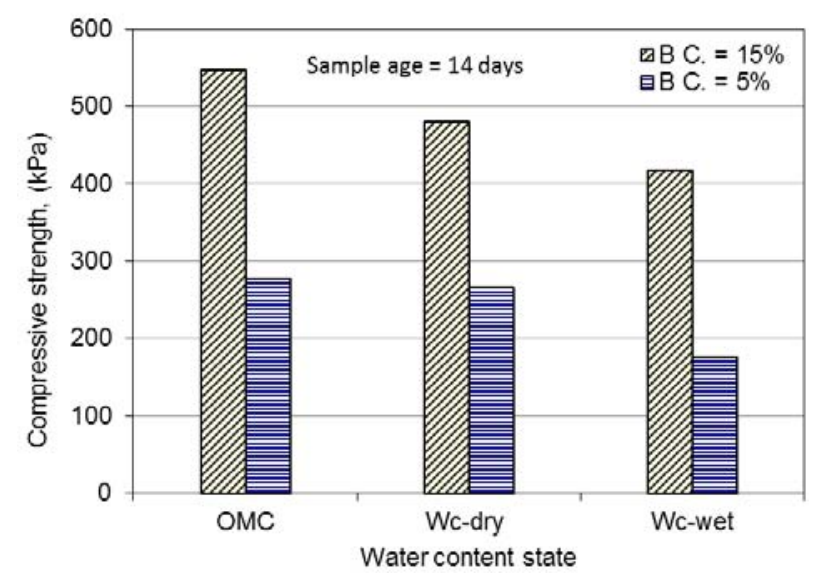

Fig. 9 Ultimate compressive strength against water content for soil type-B treated with recycled bassanite and tested after 14 days curing age. content in the case of the samples having the highest bassanite content was significant especially at moisture content in the wet-side. Furthermore, these figures in the case of samples having smallest bassanite content of $5 \%$ showed not much difference between the strength of samples prepared at moisture content in dry-side and samples prepared at optimal moisture content. This result also did not match with the theory of compaction test because these samples were impure soil. However, they were treated with some cementation materials thus their behaviors were different. In other words, the amount of moisture content in this case meets the required amount of water to complete a good reaction between cementation material and soil particles. Additionally, the decrease of water content was associated with the increase of strength. Generally, it was found that the unconfined compressive strength decreased significantly in the case of water content at wet-side that corresponding to $95 \%$ of maximum dry unit weight, while the strength of water content at dry-side was slightly decreased.

The effect of curing time on the compressive strength of untreated and treated samples with the smallest content of $5 \%$ and largest content of $15 \%$ was investigated. Consequently, five different curing times included 3, 7, 14, 28 and 56 days were studied. As aforementioned, all samples were subjected to curing under temperature $\left(21 \pm 1{ }^{\circ} \mathrm{C}\right)$ and relative humidity more than 90\%. Fig. 10 shows the effect of curing time on the compressive strength for tested soil-B at different curing times. The compressive strength for all cases, treated and untreated samples, increased as curing time increased. This finding is consistent with the theory of curing time for cementation materials. The proportion of improvement in the strength of treated samples in the early curing days was significantly higher than later curing time days. In other words, the improvement in strength for treated samples after seven days curing time was increased slowly in relation with the increase 


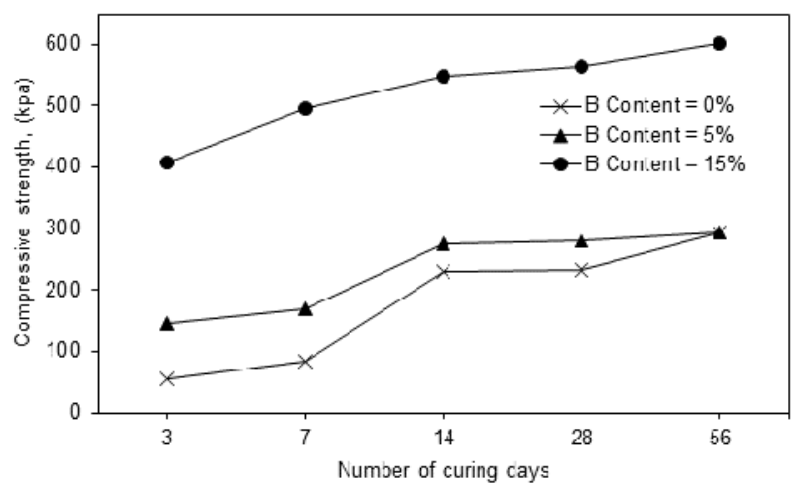

Fig. 10 Ultimate compressive strength values for soil type-B tested at different curing times.

of curing time. This behavior could be explained by the short time required to complete the setting of soil-bassanite mixture, subsequently the treated samples regained most of their strength. Hence, the improvement in strength for treated samples was evident especially in the first days of curing after which the rate of improvement was sluggish mainly with the largest gypsum content. It is worth mentioning that after 14 days of curing time for both bassanite contents, the effect of curing time was insignificant in the context of the strength improvement. The early strength for soil-bassanite mixture is actually a vital property in some projects, such as embankments. This property helps to open embankments for trafficability after compaction process directly. Subsequently, the time of construction decreases and that leads to a reduction in construction cost.

\section{Conclusions}

This research meets the challenges of society to reduce the quantities of gypsum waste plasterboards and producing useful material from waste materials. The use of recycled bassanite enhanced the performance of all the tested soils. Based on test results, the following conclusions can be drawn:

- The compressive and splitting strengths increased as recycled bassanite content increased. The content of recycled bassanite had a more significant effect on the compressive strength compared to the splitting tensile strength;

- The use of recycled bassanite enhanced the performance of all the tested types of soil. However, high performance was obtained with only sandy soil;

- Unconfined compressive strength decreased significantly in the case of water content at the wet-side compared to other cases of optimal moisture and water content at the dry-side of the compaction curve;

- The effect of curing time for samples treated with recycled bassanite was significant regarding the improvement of strength, especially in the early curing days compared with other curing says. The effect of curing time was not significant after 14 days of curing.

\section{Acknowledgments}

Funding of this research was provided through a grant from Japan Society for the Promotion of Science (JSPS) under project number P-10377.

\section{References}

[1] GRI (Gypsum Recycling International), http://www.gypsumrecycling.biz/ (accessed May 25, 2013).

[2] Z.A. Baghdadi, M.N. Fatani, N.A. Sabban, Soil modification by cement kiln dust, Material Civil Eng. J. 7 (4) (1995) 218-222.

[3] G.A. Miller, S. Azad, Influence of soil type on stabilization with cement kiln dust, Construction and Building Materials J. 14 (2) (2000) 89-97.

[4] A. Sreekrishnavilasam, S. Rahardja, M. Santagta, Soil treatment using fresh and landfilled cement kiln dust, Const. and Building Materials J. 21 (2) (2007) 318-327.

[5] A. Ahmed, M. Shehata, S. Easa, Enhancing the strength of roadway subgrades using factory-waste roof shingles, in: The Proceedings of 37th CSCE 2008 Annual Conference, Québec, Canada, June 10-13, 2008, pp. 2546-2555.

[6] A. Ahmed, M. Shehata, S. Easa, Use of factory-waste shingles and cement kiln dust to enhance the performance of soil used in road works, Advances in Civil Engineering Journal [Online early access]. DOI:10.1155/2009/143750, Dec. 2009 http://www.hindawi.com/journals/ace/2009 /143750 (accessed Feb. 1, 2013).

[7] WRAP (Waste \& Resources Action Programme), Plasterboard Technical Report: Use of Recycled Plasterboard in Unfired Clay-Gypsum Blocks, Project 
Code: PBD6-403, Banbury, Oxon, UK, 2007, www.wrap.org.uk (accessed May 25, 2013).

[8] WRAP (Waste \& Resources Action Programme), Plasterboard Case Study: Recycled Gypsum in a Novel Cementations Material, The Old Academy, 21 Horse Fair, Banbury, Oxon, UK, 2007, www.wrap.org.uk (accessed May 25, 2013).

[9] T. Kamei, T. Kato, T. Shuku, Effective use for bassanite as soil improvement materials-Recycling of waste plasterboard, Electronic Japanese Geotechnical Journal 2 (3) (2007) 245-252. (In Japanese)

[10] R.D. Holtz, W.D. Kovac, An Introduction to Geotechnical Engineering, Prentice Hall, New Jersey, 1981.

[11] A. Ahmed, K. Ugai, T. Kamei, Investigation of recycled gypsum in conjunction with waste plastic trays for ground improvement, J. Construction and Building Materials 25 (1) (2011) 208-217. 